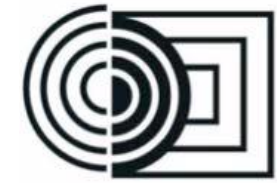

$16^{\circ}$ Ergodesign - Congresso Internacional de Ergonomia e Usabilidade de Interfaces Humano Tecnológica: Produto, Informações Ambientes Construídos e Transporte

$16^{\circ}$ USIHC - Congresso Internacional de Ergonomia e Usabilidade de Interfaces Humano Computador

CINAHPA | 2017 - Congresso Internacional de Ambientes Hipermídia para Aprendizagem.

\title{
UMA PERSPECTIVA DE DESIGN E ERGONOMIA DOS LOCAIS DE TRABALHO EM FACE DAS TECNOLOGIAS MÓVEIS
}

\section{A DESIGN AND ERGONOMIC PERSPECTIVE OF WORKPLACE IN FACE OF MOBILE TECHNOLOGIES}

\author{
Anette Correia, mestranda ${ }^{1}$ \\ Manuela Quaresma, doutora ${ }^{2}$ \\ (1) PUC-Rio, Brasil \\ e-mail: anettecorreia@hotmail.com \\ (2) PUC-Rio, Brasil \\ e-mail: mquaresma@puc-rio.br
}

Design, Ergonomia, Escritório, Móvel, Teletrabalho.

Resumo: Este artigo objetiva promover reflexões sobre o trabalho de escritório e o escritório ergonômico, considerando-se as mudanças decorrentes das tecnologias de informação e comunicação (TICs). Trata-se em especial das tecnologias móveis, de uso cotidiano do trabalhador, como smartphones, tablets e laptops, que possibilitam o trabalho móvel. Haja vista o incremento das TICs propõe-se a discussão dos modelos referentes ao escritório tradicional. Novos comportamentos, formas e demandas de trabalho foram gerados. Hoje, já são notórias as transformações nas organizações e nos ambientes de trabalho. Escritórios modernos apresentam características diferenciadas das estações de trabalho tradicionais e fixas. Entre os aspectos positivos dessas transformações, o uso das TICs no ambiente de trabalho também traz novos desafios para a ergonomia. Faz-se importante discorrer sobre a essencial contribuição das pesquisas em design e ergonomia nesse cenário de transformações propiciado pela mobilidade do trabalho.

Design, Ergonomics, Office, Mobile, Teleworking.

Abstract: This article aims to promote discussion about office work and the ergonomic office, considering the transformations caused by ICTs (Information and Communication Technologies). Among these technologies, the daily use mobile ones are notable, such as smartphones, tablets and laptops which make mobile working possible. 


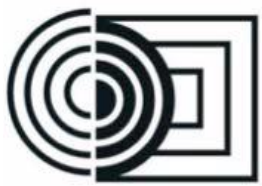

$16^{\circ}$ Ergodesign - Congresso Internacional de Ergonomia e Usabilidade de Interfaces Humano Tecnológica: Produto, Informações Ambientes Construídos e Transporte

$16^{\circ}$ USIHC - Congresso Internacional de Ergonomia e Usabilidade de Interfaces Humano Computador

CINAHPA | 2017 - Congresso Internacional de Ambientes Hipermídia para Aprendizagem.

Taking into account the ICTs, this study proposes a review of traditional ergonomic offices. New behaviors, new ways, and new demands of work took place. Today, it is remarkable how workflow and environment have changed, and modern offices have little resemblance to the ones with traditional and fixed workstations. In the midst of the bright side of such transformations, the use of ICTs by the workforce also brought new challenges related to Ergonomics. It necessary, therefore, to argue about the essential contribution by Design and Ergonomics' studies in this scenario of changes promoted by work mobility.

\section{Introdução}

Mudanças extraordinariamente rápidas têm sido constatadas em todos os setores da sociedade a partir da constituição da internet. Com o uso cotidiano das tecnologias móveis por parte do trabalhador, laptops, tablets e smartphones asseguram que as atividades de escritório possam ser realizadas mesmo longe das estações habituais de trabalho. Ainda no início do século XXI, já são notórias as transformações nas organizações em relação ao trabalho flexível. Estamos diante de um novo perfil de trabalhadores, que se conectam cada vez mais em rede móvel e digital para a execução de suas atividades laborais. Nesse contexto, o trabalhador tem executado suas tarefas nos mais diversos lugares, mantendo-se em movimento tanto dentro quanto fora do escritório, em casa ou em espaços públicos, como cafeterias, shoppings ou até em trânsito, nos meios de transporte.

Com as facilidades de acesso oferecidas pelas tecnologias de informação e comunicação (TICs), ampliaram-se as possibilidades do trabalho remoto. Neste artigo, consideram-se, inicialmente, o cenário de mudanças em relação às novas formas de trabalho remoto e os aspectos referentes ao teletrabalho em suas modalidades: home office, flexible working e mobile working. A princípio, serão abordadas questões próprias do teletrabalho, lançando sobre elas um contorno em relação à aplicabilidade dos padrões ergonômicos válidos para escritórios, como também a necessidade de ajustes desses modelos e de transposição para o trabalho móvel. Destaca-se a relevância da situação específica que precisa ser considerada com especial atenção, no caso do trabalho móvel. Apresenta-se aqui uma questão intrínseca ao trabalho móvel, que diz respeito às condições ambientais em que a tarefa é executada. Nesse cenário de escritório móvel, a abordagem ergonômica transpõe os limites das estações tradicionais de trabalho.

Ilustram-se neste trabalho também os aspectos ambientais dos escritórios modernos do século XXI e a relação das transformações internas dos espaços com a nova dinâmica das atividades de escritório e com os novos perfis dos trabalhadores. Discute-se, então, a configuração dos novos escritórios e dos novos sistemas de trabalho, representados pelo redesenho dos layouts nas organizações.

Ressalta-se a oportunidade e o potencial desse tema com a firme convicção de que as pesquisas em design muito poderão contribuir, no contemporâneo e no futuro próximo, para o desenvolvimento contínuo de projetos, produtos e espaços que traduzam as crescentes demandas da sociedade em relação ao trabalho móvel; não apenas no que se refere ao trabalho de escritório, como também nos demais segmentos incrementados pela mobilidade.

\section{A ergonomia e as novas formas de realizar o trabalho de escritório}

O foco deste artigo em relação às novas formas de trabalho escritório se volta para uma visão das questões da ergonomia no local de trabalho que é o escritório. Mas como poderemos conceituar nos dias de hoje o escritório? O que se percebe, hoje, é que o trabalho, em especial o trabalho de escritório, é feito em qualquer lugar e a qualquer hora com as facilidades de acesso remoto oferecidas pelas TICs. Classificaremos aqui, para efeito de estudos, dois tipos de escritórios: escritórios tradicionais e escritórios modernos do 


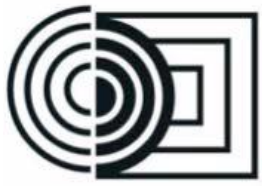

século XXI. Segundo Dainoff et al. (2012), “a resposta para o que é um escritório atualmente não é mais tão direta como há alguns anos".

Habitualmente, pode-se descrever um escritório como um local de trabalho informatizado onde se realizam tarefas administrativas. Atualmente com o intenso de dispositivos móveis, o trabalho de escritório pode ser realizado nos mais diversos lugares. "O escritório pode ser a sala de espera de um aeroporto, a mesa da cozinha de casa ou até mesmo dentro de um carro. A visão da ergonomia para o escritório tradicional poderá, então, ser adaptada e aplicada para uma situação de trabalho móvel, por exemplo, quando um trabalho é realizado com a utilização de um laptop em um quarto de hotel ou em estações de trabalho em home office ".(DAINOFF et al., 2012, p. 1551).

As tecnologias móveis não apenas modificaram o ambiente do escritório internamente como conferiram mobilidade às atividades de trabalho de escritório. Na visão de Andrade (2013), "a necessidade de espaço físico está cada vez mais relacionada com a cultura organizacional, bem como com a distribuição dos ambientes". O que se percebe é que as pessoas mudaram seus hábitos e rotinas, aproveitando brechas do tempo para realizar suas atividades pessoais e profissionais de forma híbrida. Alternando trabalho com não trabalho em intervalos cada vez menores e mais imperceptíveis, tornou-se mais difícil hoje, para o trabalhador, diferenciar o espaço de tempo dedicado a cada atividade separadamente. Considerando-se a forma como hoje em dia aproveitamos pequenos intervalos de tempo para realizar tarefas e muitas vezes as realizamos de forma simultânea, é comum dividirmos a atenção e o tempo entre trabalho e vida pessoal sem uma distinção rígida que delimite a natureza dessas ações. Ressalta-se a importância do enfoque de como o trabalho de escritório está sendo realizado na atualidade sob a ótica da ergonomia, disciplina que estuda o trabalho e o indivíduo e, de acordo com Pheasant (2003), "com que equipamentos e ferramentas, e em que locais esse trabalho ocorre, bem como quais são os aspectos físicos e psicossociais dessas situações de trabalho". $16^{\circ}$ Ergodesign - Congresso Internacional de Ergonomia e Usabilidade de Interfaces Humano Tecnológica: Produto, Informações Ambientes Construídos e Transporte

$16^{\circ}$ USIHC - Congresso Internacional de Ergonomia e Usabilidade de Interfaces Humano Computador

CINAHPA | 2017 - Congresso Internacional de Ambientes Hipermídia para Aprendizagem.

\subsection{O teletrabalho}

Teletrabalho, de acordo com a Organização Internacional do Trabalho (OIT), "é o trabalho executado com o uso de novas TICs que acontece remotamente, em um local distante do escritório central" (PRETTI, 2009). Em plena expansão no Brasil e no mundo e superando as barreiras espaciais e temporais, o teletrabalho vem sendo adotado em diversos setores da sociedade, oferecendo flexibilidade em relação a locais e a horários de trabalho. O físico Jack Nilles, que trabalhava para a Nasa, desenvolveu esse conceito e cunhou o termo teleworking (teletrabalho) em 1973, e desde então é considerado o pai do teletrabalho. Em meio à crise mundial do petróleo, Nilles percebeu essa mudança de paradigma, que "levava o trabalho ao ser humano, e não obrigatoriamente este ao trabalho, como uma solução para otimizar o aproveitamento dos recursos energéticos não renováveis". Desde então, Nilles tem se dedicado à expansão dessa modalidade de trabalho (NILLES, 2001). Em 1980, fundou a consultoria Jala International, em Los Angeles, que promove e divulga o teletrabalho em diversos países em todo o mundo.

Muitas questões de sustentabilidade são levantadas em favor do teletrabalho. Como defendem Jack Nilles e os profissionais da Jala International, com a expansão das atividades remotas, diminuindo-se a necessidade de deslocamento do trabalhador em direção ao local de trabalho, haverá uma expressiva redução da poluição e da emissão de gás carbônico, e ainda grande redução de gastos, entre outras vantagens. De acordo com a natureza de sua atividade de trabalho, o teletrabalhador pode trabalhar em seu domicílio, em viagem ou ser destacado para outros centros de trabalho. Esses centros podem ser da mesma empresa, de seus fornecedores ou clientes. Dessa forma, as atividades de teletrabalho apresentam diferenças quanto à mobilidade do trabalho, sendo estas: "trabalho em domicílio (home-based ou home office); trabalho flexível (flexible working); e trabalho móvel (mobile working)". 


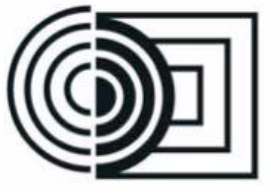

$16^{\circ}$ Ergodesign - Congresso Internacional de Ergonomia e Usabilidade de Interfaces Humano Tecnológica: Produto, Informações Ambientes Construídos e Transporte

$16^{\circ}$ USIHC - Congresso Internacional de Ergonomia e Usabilidade de Interfaces Humano Computador

CINAHPA | 2017 - Congresso Internacional de Ambientes Hipermídia para Aprendizagem.
$\mathrm{O}$ advento da internet e sua popularização foram significativos para o incremento do trabalho remoto; entretanto, pode-se inferir que foi pela facilidade de acesso e de uso das tecnologias móveis que o teletrabalho passou a atingir as mais tênues camadas sociais de trabalhadores. Assim, entre as ferramentas de trabalho utilizadas pelos teletrabalhadores, os dispositivos móveis merecem um especial destaque em relação à sua importância na disseminação dessa forma de trabalho. Afirma McKeown (2007) a respeito dos laptops que, "assim que foram introduzidos nos locais de trabalho, proporcionaram a oportunidade de as pessoas trabalharem fora do ambiente do escritório". De acordo com o autor, com o laptop as pessoas poderiam trabalhar em um trem, em um hotel, durante uma conferência, uma reunião ou em casa, utilizando o equipamento. Conclui McKeown (2007) que cada vez mais as pessoas começaram a ter preferência por trabalhar com laptops durante todo o dia, seja dentro ou fora do escritório, e afirma, " com o passar dos anos, os laptops foram conduzidos também para o uso mais contínuo dentro do ambiente do escritório, substituindo em parte os computadores fixos".

Nesse contexto de célere escalada tecnológica, podem-se observar mudanças no perfil do trabalho em todo o mundo. Em 2015, a OIT apresentou um relatório que aponta para o crescimento expressivo do trabalho em casa, do trabalho flexível e dos vínculos informais de trabalho. Sobre os resultados desse mais recente relatório da OIT, comenta a repórter Mariana Branca, da Agência Brasil: ${ }^{1}$ "trabalhadores em arranjos que destoam do padrão representam três quartos dos empregados no mundo. Para especialistas, as novas formas de trabalho precisam de regulação".

Os pesquisadores Patrick Jordan e Jim Taylour (2015), da Loughborough University (Inglaterra), apontam em suas publicações para a mudança no mundo do trabalho que envolve o uso das tecnologias móveis e o trabalho a distância. Transformações nas rotinas dos trabalhadores de

\footnotetext{
${ }^{1}$ Agência Brasil. Disponível em:
} <http://agenciabrasil.ebc.com.br>. escritório relacionadas com a diminuição do tempo que passam em sua estação de trabalho fixa já podem ser observadas. "A predominância do uso dos dispositivos móveis na atualidade favorece a opção pelo trabalho em movimento, o trabalho móvel, de modo que possa ser realizado em diversos locais e ambientes, inclusive em ambientes alternativos dentro do escritório, longe da estação de trabalho habitual do trabalhador".(JORDAN; TAYLOUR, 2015).

\subsection{O trabalho em casa: home offices}

As empresas cada vez mais tem enxergado o teletrabalho como uma solução para racionalizar atividades e diminuir custos fixos de infraestrutura. Diante da possibilidade de ter funcionários trabalhando em casa, reduzem-se os espaços físicos da empresa, que passam a ser usados de forma compartilhada, sem estações fixas definidas para cada trabalhador. Entre os benefícios Konradt (2000) destaca a satisfação do empregado com o trabalho. "Trabalhar em casa permite uma série de ajustes, como a economia do tempo utilizado em deslocamento no trânsito. Destacam-se ainda, entre os ganhos decorrentes do trabalho em casa citados pelos profissionais, a independência, a produtividade e a organização do tempo"(KONRADT et al., 2000).

Entende-se que os escritórios de home office devem ser planejados para o teletrabalho, e os ambientes de trabalho no domicílio do trabalhador devem passar pela supervisão da área de prevenção em segurança e saúde da empresa, da mesma forma que os ambientes de trabalho internos das corporações. Algumas empresas já têm assumido a montagem e a manutenção dos escritórios de teletrabalho home office, no sentido de garantir a instalação das condições favoráveis e adequadas ao trabalho. No Brasil, o teletrabalho é legislado pela Lei ${ }^{\circ} 12.551$, de 16 de dezembro de 2011, que equipara o trabalho virtual, por meios telemáticos informatizados, ao trabalho presencial. Dessa forma, os ambientes de trabalho do trabalhador em regime de teletrabalho devem acompanhar o que preconiza a norma reguladora da ergonomia NR17. De acordo com a legislação vigente, "trabalhadores
Realização:

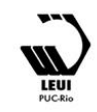

\section{UNIVERSIDADE FEDERAL} DE SANTA CATARINA 


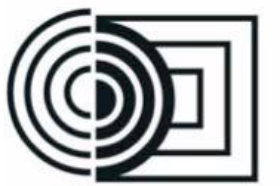

de teletrabalho vinculados às empresas, mesmo em regime home office, permanecem sob a supervisão, ainda que virtual, da empresa para a qual trabalham. As empresas devem manter o controle dos resultados e da produtividade do teletrabalhador, que permanece vinculado ao regime de metas e promoções".

\subsection{O trabalho flexível e o trabalho móvel}

É desejável que, antes que se atribua uma atividade ao trabalhador flexível ou móvel, seja feita uma avaliação ergonômica da atividade, certificando-se de que maneira esta pode melhor se adequar à mobilidade. Essa etapa pode auxiliar a prever as situações de trabalho, a fim evitar danos para o trabalhador ou perdas para a empresa. Do ponto de vista ergonômico, é necessário mapear a atividade de trabalho em suas complexidades, como também verificar o perfil dos trabalhadores considerando-se suas características, habilidades e limitações, assim como, projetar os possíveis cenários de uso das ferramentas de trabalho dos trabalhadores móveis para otimizar as condições de execução das tarefas. Dainoff (2012) destaca o fato de que "nas últimas décadas, assistimos a algumas grandes mudanças físicas, organizacionais, como também psicossociais no ambiente de escritório. Ressalta-se entre elas, a aceitação do trabalho flexível na cultura organizacional dos escritórios. "Em algumas situações de trabalho" remoto, além de computadores, laptops, tablets e smartphones são necessários disponibilizar um telefone fixo com secretária eletrônica, computadores fixos, impressoras, scanner e ainda ter acesso às redes sociais, aplicativos, sites de pesquisa, enfim, tudo que possa contribuir para a plena realização de suas atividades. É usual que no trabalho flexível e trabalho móvel o trabalhador se utilize de dispositivos móveis fornecidos pela empresa e acesso aos softwares coorporativos". (DAINOFF et al., 2012, p. 1555). Com o trabalho flexível, um novo estilo de vida da sociedade se revela. Conjugado aos aspectos positivos do trabalho móvel e em meio à sua ampla e internacional expansão, ainda é visível uma carência de ambientes projetados por designers $\mathrm{e}$ disponibilizados para o uso dos trabalhadores móveis em atividade. Espaços improvisados, mesas ou bancadas escassas e com suportes físicos reduzidos são disputadas pelos trabalhadores quando necessitam realizar uma tarefa rápida ou urgente com um laptop nos espaços públicos urbanos. Nem mesmo os restaurantes, cafeterias ou shoppings parecem estar preparados para atender à crescente demanda do trabalho móvel. Alguns trabalhadores móveis por vezes recorrem aos escritórios de coworking. Estes, também em expansão, têm se apresentado como uma opção, disponibilizando condições mais favoráveis à realização dessas atividades.

A posição de Lazlo (2015) acerca da digitação contínua em tela de vidro nos tablets e smartphones e da utilização do teclado e do mouse em condições ambientais adversas é de que, "por não oferecem apoio suficiente, podem motivar a adoção de posturas forçadas, com consequentes danos ao sistema musculoesquelético do indivíduo". Também em relação à utilização numerosa e crescente de laptops, o entendimento do autor é de que esse fato "contribui para o surgimento dos problemas osteomusculares na população". Se, por um lado, são oferecidos praticidade e conforto com a portabilidade e também economia do espaço com os laptops, para Lazlo (2015) "é impossível trabalhar com eles mantendo uma postura apropriada".

Em relação aos aspectos ergonômicos, é necessário observar as dimensões físicas, cognitivas e psíquicas que permeiam a atividade do trabalhador móvel. Acredita-se que dessa análise possam surgir oportunidades de projetos e incrementos positivos nas pesquisas em relação às condições de trabalho no que tange à mobilidade do trabalho de escritório. Ainda sob a ótica da ergonomia, de acordo com Stammers (1990 apud MORAES; MONT'ALVÃO, 2009, p. 153), destacam-se aqui "os fatores que influenciam o processo de análise das tarefas que devem ser observados e estudados: os requisitos da tarefa, o ambiente da tarefa e o comportamento da tarefa". Se, por um lado, a liberdade de escolha do trabalhador móvel para decidir o momento e o ambiente de execução de seu trabalho o favorece, reduzindo condicionantes 


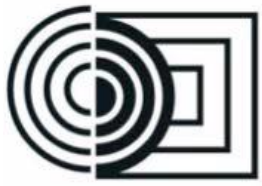

$16^{\circ}$ Ergodesign - Congresso Internacional de Ergonomia e Usabilidade de Interfaces Humano Tecnológica: Produto, Informações Ambientes Construídos e Transporte

$16^{\circ}$ USIHC - Congresso Internacional de Ergonomia e Usabilidade de Interfaces Humano Computador

CINAHPA | 2017 - Congresso Internacional de Ambientes Hipermídia para Aprendizagem. da carga de trabalho, determinados, de acordo com Moraes e Mont'Alvão (2009, p. 52), como “carga externa", por outro, em razão de o contexto de mobilidade ser flexível e mutável, existem dificuldades no trabalho móvel em projetar e realizar predições para o trabalhador quanto ao ambiente da tarefa. Embora livre dessas cargas externas no âmbito da ambiência organizacional, o próprio trabalhador passa a discernir outras questões referentes à carga externa, que são a ambiência física e operacional de sua tarefa.

Diante dessas transformações no mundo do trabalho, pode-se reconhecer a popularidade do trabalho flexível pelos relatos e pesquisas divulgadas, bem como a satisfação pessoal apontada entre os trabalhadores de escritório. Pelo que se pode observar, a possiblidade de conciliar afazeres da vida pessoal com as obrigações do trabalho tem gerado maior adesão ao trabalho flexível, e sua repercussão está constantemente relacionada com a percepção de melhoria na qualidade de vida. O Comitê de Ergonomia da International Ergonomics Association (IEA) (DULL et al., 2012) discute, entre outras questões, o futuro e a evolução da ergonomia e aponta para "estratégias que desenvolvam o potencial das pesquisas em fatores humanos, reforçando sua imensa contribuição para aperfeiçoar o desempenho e o bem-estar social". De acordo com Dull et al. (2012), "praticantes de ergonomia podem contribuir para o planejamento, o design, a implementação, a avaliação, o redesign e melhorias contínuas de trabalhos e projetos". O objetivo deste artigo converge com o crescimento do trabalho móvel e demais fatores que favorecem o reconhecimento de novas demandas e oportunidades de projetos voltados para esse público de trabalhadores e para a sociedade em geral.

\section{Os escritórios do século XXI: o design e a ergonomia nos novos espaços de trabalho}

As novas formas de trabalho têm repercutido também na diversidade de ambientes do escritório contemporâneo. A aparente modificação dos layouts internos das empresas verificada hoje nos escritórios modernos do século XXI reforça a prevalência do uso dos dispositivos móveis. Corrobora-se aqui o pensamento de Pheasant (2003) em relação à abordagem ergonômica de um projeto que, segundo o autor "pode ser resumida em um design centrado no usuário. O projeto de um ambiente deve ser baseado nas características físicas e mentais de quem for utilizá-lo, com o objetivo de alcançar a melhor correspondência possível no contexto da atividade que será executada" (PHEASANT, 2003, p. 5). Observa-se que as estruturas físicas do escritório, na atualidade, traduzem expectativas por agilidade e mobilidade presentes na dinâmica empresarial da atualidade e nos novos perfis e demandas dos trabalhadores que buscam conciliar muitas atividades em seu dia a dia. Os arquitetos holandeses Meel et al. (2013) ressaltam que "o ambiente de trabalho flexível também está associado às constantes mudanças nos processos de trabalho e nas estruturas coorporativas". De acordo com os autores, seguindo esse padrão, simplificase e reduz-se o custo das adaptações, como também o impacto das mudanças nas rotinas diárias. Um exemplo disso são as estações de trabalho temporárias que combinam perfeitamente com soluções just in time, como pode ser observado na Figura 1.

Estação de trabalho flexível na qual as pessoas executam as atividades em pé.

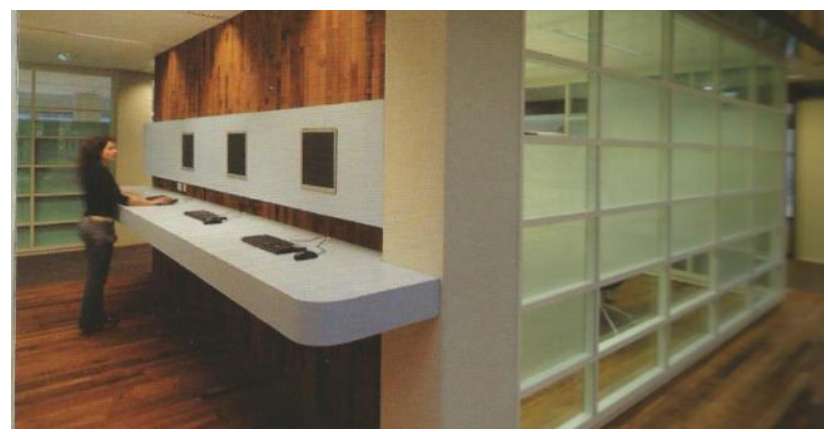

Figura 1 - Estações temporárias proporcionam um espaço para a realização de tarefas rápidas, como a verificação de e-mails (VU University, Amstelveen, Holanda. Design: Hollands Nieuwe). 


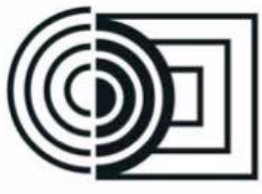

ERGODESIGN USIHC CINAHPA $16^{\circ}$ Ergodesign - Congresso Internacional de Ergonomia e Usabilidade de Interfaces Humano Tecnológica: Produto, Informações Ambientes Construídos e Transporte

$16^{\circ}$ USIHC - Congresso Internacional de Ergonomia e Usabilidade de Interfaces Humano Computador

CINAHPA | 2017 - Congresso Internacional de Ambientes Hipermídia para Aprendizagem.
Fonte: Meel et al., 2013, p. 56.

Em seu estudo sobre os escritórios do século XXI, Andrade (2013) aponta, diante de estudos de casos de transformações ambientais nos escritórios modernos, algumas situações que sinalizam as demandas nos layouts atuais das empresas, como: "criação de espaços de reunião informal, espaços de trabalhos de curta permanência e espaços de relaxamento, chamados espaços de regeneração". Neste novo modelo, reduzem-se os espaços de incrementar a interação, é desejável eliminar as barreiras físicas entre os trabalhadores do escritório. Como apresentam as Figuras 2 e 3, os modernos escritórios do século XXI convivem com espaços como: estações de espaços abertos de colaboração, casulos individuais, estações temporárias de trabalho ou ainda outros espaços de convivência ao ar livre, concebidos para a descompressão dos trabalhadores de pressões diárias. Entre as questões ergonômicas nos escritórios abertos, ressalta-se a atenção ao tratamento acústico, com o objetivo de prevenir os ruídos e interferências negativas nos ambientes de trabalho, em especial nos espaços voltados para a realização de atividades que exijam esforço cognitivo e concentração. O fato de ser cada vez mais habitual o trabalhador ter seu próprio laptop nos remete à necessidade de projetos ergonômicos para a adaptação desses equipamentos nos escritórios que ainda não se ajustaram a essa realidade. Acredita-se que as pesquisas em design e ergonomia possam contribuir de forma significativa para o desenvolvimento contínuo de ambientes adequados aos avanços tecnológicos que influenciam diretamente o trabalho móvel.trabalho de longa permanência e aumentam os espaços de circulação e de reuniões formais. Observa-se que o redesenho dos escritórios do século XXI apresenta diversos ambientes de fácil montagem e paredes móveis. Dessa forma, os locais em que se reúnem grupos de cooperação para projetos podem ser transformados em espaços de reuniões formais ou compartimentados em espaços mais reduzidos, direcionados para atividades de isolamento e concentração; ambientes ágeis, que favoreçam a variação de atividades. Os escritórios modernos precisam ser flexíveis, práticos e versáteis e "oferecer aos trabalhadores e às empresas controle e escolhas sobre seu ambiente" ANDRADE (2013). Nesse contexto, vivenciamos hoje a predominância de uma cultura colaborativa que busca inspirar a criatividade entre os trabalhadores. Para

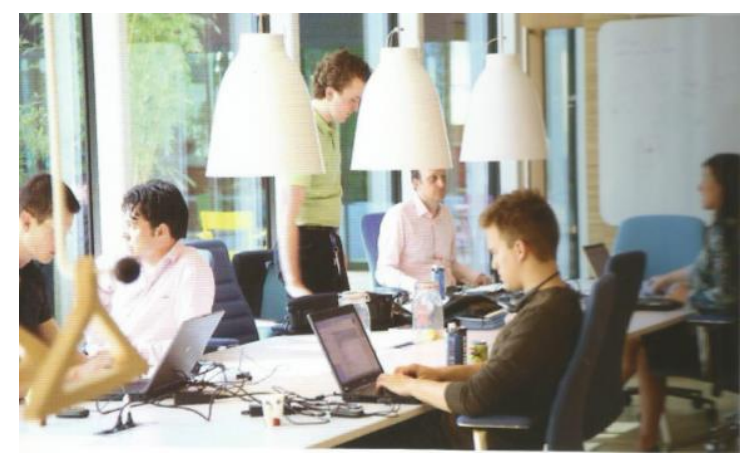

Figura 2 - $O$ trabalho colaborativo requer interação espontânea frequente entre a equipe. Escritório da Microsoft, em Amsterdã, Holanda. Fonte: Meel et al., 2013, p. 50.

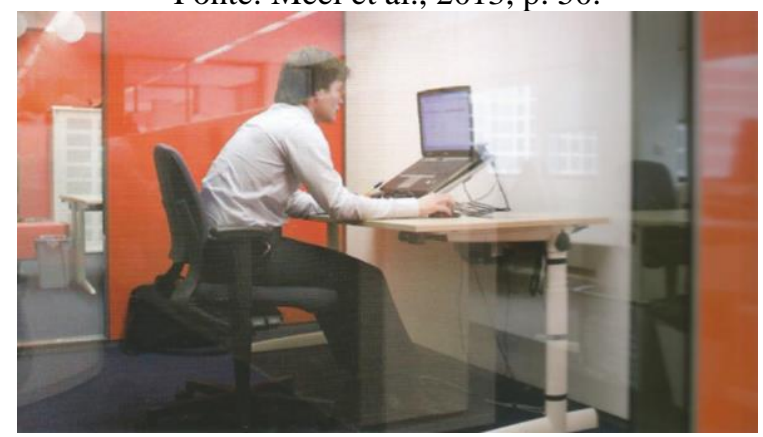

Figura 3 - Cabines individuais não territoriais para uso por períodos curtos (de uma ou duas horas). Escritório da TNT, em Haia, Holanda. Fonte: Meel et al., 2013, p. 52.

De acordo com Pheasant (2003), "nas últimas décadas os escritórios têm se baseado cada vez mais em meios eletrônicos". A recomendação ergonômica do autor para a utilização de computadores, telas, teclados e periféricos é de que "a superfície da mesa do usuário seja um pouco acima do cotovelo para manter uma ação natural, sem posturas forçadas. Para o trabalho com o teclado", os "ombros devem estar relaxados, e os pulsos, em posição neutra. Olhando para o centro da tela, a linha de visão deve ser aproximadamente perpendicular à superfície da tela. Para atender a esses requisitos, a tela precisaria estar separada do 


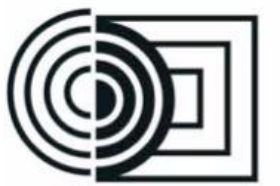

teclado, podendo ser ajustada em suporte adequado para essa função" (PHEASANT, 2003, p. 93). No entanto, Iida (2016) observa que "as estações de trabalho convencionais e tradicionais estão cada vez mais escassas, e as que se perpetuam têm sido direcionadas mais comumente para trabalhos administrativos". Segundo o autor, a introdução dos microcomputadores na década de 1980 provocou uma "profunda mudança na natureza do trabalho em escritórios, afetando o uso dos recursos e as próprias posturas de trabalho" (IIDA, 2016, p. 770).

O surgimento dos laptops proporcionou às pessoas a oportunidade de dar prosseguimento ao trabalho mesmo estando fora do escritório. Assim, poderiam trabalhar em casa, em um hotel, durante uma conferência ou mesmo dentro de um avião. Conforme o tempo avançava, os laptops foram trazidos para dentro do escritório. "Hoje, cada vez mais nota-se a preferência dos trabalhadores por utilizar laptops, levando-os consigo para onde forem, durante todo o dia" (MCKEOWN, 2007). O aumento do uso dos laptops, de acordo com Pheasant (2003), "é um agravante em relação às posturas mantidas, com especial preocupação em relação à altura da tela". No entanto, o autor prossegue discorrendo que os laptops permitem a inclinação da tela. "Inclinar a tela para frente ou para trás possibilita ao usuário a escolha do melhor ângulo para sua adaptação, o que atenua a situação" (PHEASANT, 2003, p 100).

Em muitos escritórios e reuniões de trabalho, observamos o uso dos tablets, inclusive tablets coorporativos, que acompanham os executivos em suas atividades, reuniões e viagens. A vantagem da versatilidade do tablet pode também ser um problema sob a ótica do desconforto para o trabalhador. É o que afirmam alguns pesquisadores do tema (YOUNG et al., 2012 apud JORDAN; TAYLOUR, 2015; STAWARZ et al., 2013 apud JORDAN; TAYLOUR, 2015). "Durante o uso prolongado do tablet, ao adotar a postura de pescoço flexionado para ler a tela, conjugado com a digitação excessiva nela, observa-se o aumento de lesões de pescoço, pulso e mão", afirmam os autores. De acordo com Pheasant (2003), para a $16^{\circ}$ Ergodesign - Congresso Internacional de Ergonomia e Usabilidade de Interfaces Humano Tecnológica: Produto, Informações Ambientes Construídos e Transporte

$16^{\circ}$ USIHC - Congresso Internacional de Ergonomia e Usabilidade de Interfaces Humano Computador

CINAHPA | 2017 - Congresso Internacional de Ambientes Hipermídia para Aprendizagem. prevenção da fadiga tanto física quanto mental, é necessário realizar pausas da atividade. " $\mathrm{O}$ trabalhador de escritório deve ser fortemente encorajado a levantar-se e a movimentar-se e relaxar. Dessa forma, quando o grau adequado de diversidade das tarefas não pode ser razoavelmente alcançado, o período de trabalho deve ser estruturado prevendo pausas curtas de recuperação da fadiga" (PHEASANT, 2003, p. 104).

Os pesquisadores Jordan e Taylour (2015) apresentam um ranking de equipamentos mais utilizados durante a semana por 80 trabalhadores de escritório. Os achados apontam, em primeiro lugar, para o uso do smartphone coorporativo, seguido do laptop, do computador da estação de trabalho pessoal, do tablet e, por último, do smartphone pessoal. Pode-se deduzir por inferência, por meio desses dados de pesquisa e do contexto de trabalho em que vivemos a existência de uma forte associação do smartphone com as atividades laborais, em que ele se destaca de forma predominante em relação aos demais dispositivos móveis. A importância do smartphone é frequentemente apontada, bem como seu papel nas tecnologias de trabalho com a facilidade de operacionalização das ações tecnológicas acessadas por empresas e empregados por meio do smartphone coorporativo. Dessa forma, pode-se considerar o smartphone como marco decisivo para a mobilidade do trabalho.

No Brasil, foi divulgada, em abril de 2016, a pesquisa PNAD TIC $2014,{ }^{2}$ que revelou que o acesso à internet por meio de telefones celulares nos domicílios ultrapassou o acesso por microcomputador. É a primeira vez que isso ocorre, o que indica um expressivo aumento do uso de celulares nos domicílios para acesso à rede. ${ }^{3}$ Finalmente, conclui-se que, nas áreas urbanas, $82,3 \%$ da população a partir dos 10 anos ou mais

\footnotetext{
${ }^{2}$ Posição dos domicílios em relação às TICs da Pesquisa Nacional de Amostra de Domicílios (PNAD) de 2014. Foram analisados, entre outros dados, o acesso à internet e os tipos de aparelhos eletrônicos utilizados.

${ }^{3} \mathrm{O}$ uso de celulares passou de 53,6\% para 80,4\% de 2013 para 2014. A utilização de microcomputadores, no mesmo período, recuou de $88,4 \%$ para $76,6 \%$.
}

Realização:
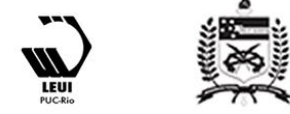


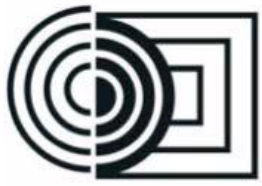

$16^{\circ}$ Ergodesign - Congresso Internacional de Ergonomia e Usabilidade de Interfaces Humano Tecnológica: Produto, Informações Ambientes Construídos e Transporte

$16^{\circ}$ USIHC - Congresso Internacional de Ergonomia e Usabilidade de Interfaces Humano Computador

CINAHPA | 2017 - Congresso Internacional de Ambientes Hipermídia para Aprendizagem. de idade possui celular. Tais mudanças desdobramse em novos comportamentos e hábitos de vida. A sociedade repensa suas formas de convivência e interação tanto no trabalho quanto em família a partir de uma realidade que se alterna entre o presencial e o virtual.

Há muitos anos, o sedentarismo tem sido tradicionalmente uma grande preocupação no que tange aos riscos para a saúde do trabalhador. Isso acontece em razão de a natureza do trabalho intelectual contribuir para que o indivíduo permaneça concentrado na atividade por diversas horas do dia, sentado à frente do computador. Nos escritórios modernos voltados para a atividade, móveis de escritório que permitem ficar em pé durante o trabalho (sit-stand) e estações alternativas que reduzem o tempo sentado do trabalhador, permitindo um gasto calórico ao caminhar e até andar de bicicleta (Figura 4), estão modificando essa realidade. "Junto com ações e recomendações ergonômicas, a implantação dos escritórios voltados para a atividade tem promovido a variação de posturas e a movimentação com pequenas caminhadas no ambiente de trabalho". (HUYSMANS et al., 2015).

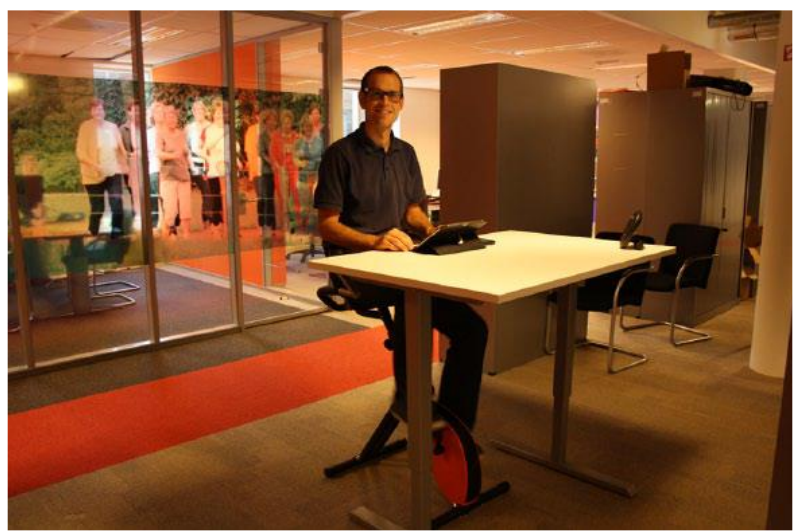

Figura 4 - Circle ergonometer sitting upright - source deskbike.

Fonte: Huysmans et al., 2015, p. 4.

Corrobora-se, aqui, o pensamento de Iida (2016) quanto ao fato de que, "embora hoje já existam muitos móveis adequados aos postos de trabalho informatizados (MORAES; PEQUINI, 2000 apud IIDA, 2016), ainda subsistem muito postos adaptados e improvisados, principalmente no ambiente doméstico" (IIDA, 2016, p. 770). Entende-se que essa seja uma necessidade que pode também ser estendida a locais que se destinem aos trabalhos temporários para trabalhadores móveis, em espaços comerciais, privados ou ainda em espaços públicos urbanos, sobretudo e considerando a prevalência de uso das tecnologias móveis entre a população em uma sociedade e em um mundo cada vez mais digitais.

\section{Conclusão}

Muitas mudanças estão ainda por vir com os avanços tecnológicos e o contínuo incremento das TICs nas atividades de trabalho, visto que o número crescente do uso de tecnologias móveis tem contribuído para a consolidação de novos hábitos do trabalhador. Independentemente da faixa etária ou da geração — analógica ou digital - do indivíduo, é possível perceber que a dinâmica de trabalho exige, hoje, uma lógica atemporal e extraterritorial, fortemente inserida desde a popularização da internet. Os espaços dos escritórios estão sendo redefinidos, e as estações móveis e temporárias ganham lugar. De fato, é necessário conduzir a discussão para modelos e recomendações ergonômicos que considerem as circunstâncias de mobilidade que englobam esses novos modos e ambientes de trabalho. Diante de uma realidade que contempla práticas de trabalho a distância e a adoção de ambientes internos e externos, privados e públicos, entende-se que as propostas para ergonomia devam estar além dos limites das estações de trabalho fixas. Ou seja, fazse imprescindível considerar a adequação das questões ergonômicas que envolvem o trabalhador de escritório em tempos de mobilidade.

Como propôs este artigo, o delineamento de uma nova dinâmica nos novos ambientes de trabalho pode beneficiar trabalhadores e empresas, favorecendo o bem- estar dos trabalhadores e aumentando sua eficiência. As transformações decorrentes da implantação de mobilidade no trabalho, por exemplo, reduzem o sedentarismo associado aos escritórios fixos. Porém, o 


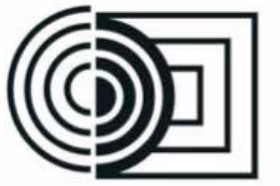

aprofundamento dos novos sistemas de trabalho dos escritórios modernos ressalta a importância de que esses fatores devam ser analisados em conjunto com os desafios e as limitações apontados com o uso prolongado dos dispositivos móveis. Pelo estudo das novas rotinas dos trabalhadores móveis, dentro e fora do escritório, faz-se possível uma melhor compreensão das profundas mudanças que ocorrem em relação ao trabalho de escritório, às novas formas de trabalho e aos novos espaços laborais no cotidiano da sociedade. Em conclusão, acredita-se na importância de futuros estudos e pesquisas em design que possam analisar as demandas e as adaptações necessárias aos trabalhadores diante das novas situações de trabalho.

\section{BIBLIOGRAFIA}

ANDRADE, Cláudia. O escritório do século XXI. São Paulo: C4, 2013.

DAINOFF, Marvin; MAYNARD, Wayne; ROBERTSON, Michelle; ANDERSEN, Johan Hviid. Office ergonomics: handbook of human factors and ergonomics. Edição de Gavriel Salvendy. 4. ed. Nova Jersey: John Wiley \& Sons, Inc. 2012. Cap. 56.

DULL, Jan; BRUDER, Ralph; BUCKLE, Peter; CARAYON, Pascale; FALZON, Pierre; MARRAS, William S.; WILSON, John R.; DOELEN, Bas van der. A strategy for human factors/ergonomics: developing the discipline and profession. Institute of Ergonomics \& Human Factors, IEA, 2012.

HUYSMANS, Maiake A.; PLOEG, Hidde P. van der; PROPER, Karin I.; SPEKLÉ, Erwin M.;

BEEK, Alalard J. van der. Is Sitting to much bad for your health? Ergonomics in Design, Jul. 2015.

IIDA, Itiro. Ergonomia: projeto e produção. 2. ed. São Paulo: Edgard Blucher, 2016.

JORDAN, Patrick; TAYLOR, Jim. The psychology of the mobile working: productivity $16^{\circ}$ Ergodesign - Congresso Internacional de Ergonomia e Usabilidade de Interfaces Humano Tecnológica: Produto, Informações Ambientes Construídos e Transporte

$16^{\circ}$ USIHC - Congresso Internacional de Ergonomia e Usabilidade de Interfaces Humano Computador

CINAHPA | 2017 - Congresso Internacional de Ambientes Hipermídia para Aprendizagem. and wellbeing of contemporary workplace. In: $17^{\mathrm{a}}$ INTERNATIONAL CONFERENCE ON HUMAN COMPUTER INTERACTION - HCI 2015. Anais..., Los Angeles, 2015.

KONRADT, U.; SCHMOOK, R.; MÄLECKE, M. Impacts of telework on individuals, organizations and families: a critical review. International Review of Industrial and Organizational Psychology, v. 15, p. 63-98, 2000.

LASZLO, Berenyi; SZOLNOKI, Bernadett; BANHEGYESI, Lajos. Office work: ergonomic and medical aspects. European Scientific Journal, Academic OneFile [web], v. 11.2, p. 21, 7 Jun. 2015.

MCKEOWN, Céline. Office ergonomics: pratical applications. EUA: CRC Press, 2007.

MEEL, Juriaan van; MARTENS, Yuri; REE, Hermes Jan van. Como planejar os espaços de escritórios: guia prático para gestores e designers. Tradução de Beth Ardións. São Paulo: Gustavo Gili, 2013.

MORAES, Anamaria; MONT'ALVÃO, Claudia. Ergonomia: conceitos e aplicações. Rio de Janeiro: 2AB, 2009.

NILLES, Jack. Managing telework. Canadá: John Willey \& Soons, Inc., 2001.

PHEASANT, Steven. Bodyspace, anthropometry, ergonomics and the design of work. Londres: Taylor \& Francis, 2003.

PRETTI, Gleibe. Direito internacional do trabalho e convenções da OIT ratificadas pelo Brasil. São Paulo: Îcone, 2009.

SALVENDY, Gavriel. Handbooks of human factors and ergonomics-office ergonomics. Hoboken, N.J.: John Wiley \& Sons, Inc., 2012.

SAVAL, Nikil. Cubilados: uma história secreta do local do trabalho. Tradução de Angela Lobo de Andrade. 1. ed. Rio de Janeiro: Anfiteatro, 2015. 


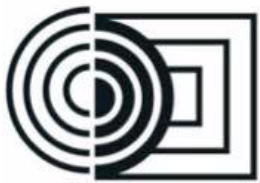

$16^{\circ}$

ERGODESIGN USIHC CINAHPA $16^{\circ}$ Ergodesign - Congresso Internacional de Ergonomia e Usabilidade de Interfaces Humano Tecnológica: Produto, Informações Ambientes Construídos e Transporte

$16^{\circ}$ USIHC - Congresso Internacional de Ergonomia e Usabilidade de Interfaces Humano Computador

CINAHPA | 2017 - Congresso Internacional de Ambientes Hipermídia para Aprendizagem.

TAYLOUR, Jim. Physical discomfort and mobile working: wellbeing approach to healthy best practice. In: 17 INTERNATIONAL CONFERENCE ON HUMAN COMPUTER INTERARION. Anais... Los Angeles, 2015.

TELETRABALHO: prevenção à distância.

Revista Proteção, v. 282, n. 167, jun. 2015.

\section{Agradecimentos}

As autoras agradecem à Capes o apoio disponibilizado como instituição de fomento, possibilitando o desenvolvimento deste trabalho. 